ISSN: 2146-3042

DOI:

\title{
Genelleştirilmiş Hiperbolik Çarpık Student t Dağılım Varsayımına Dayalı Asimetrik Stokastik Volatilite Modelinin Türk Döviz Piyasasına Uygulanması*
}

\author{
ÖNDER BÜBERKÖKÜ**
}

\section{$\ddot{O Z Z E T}$}

$B u$ çalışmada genelleştirilmiş hiperbolik çarpık student $t$ dağılım varsayımına dayalı asimetrik stokastik volatilite modeli Bayesyen yaklaşımına dayalı MCMC (Markov Chain Monte Carlo, MCMC) algoritması kullanılarak Dolar-TL ve Euro-TL kurlarına uygulanmıștır. Çalıșma bulguları bu güncel modelinin Türk döviz piyasalarına etkin bir șekilde uygulanabileceğine ișaret etmektedir. Bulgular, yüksek volatilite kalıcıllğının ve asimetrik tepkinin her iki döviz kuru için de geçerli olduğu ve Dolar-TL volatilitesinin öngörülebilirliğinin Euro-TL volatilitesine göre daha zor olduğunu göstermektedir. Modelin sunduğu stokastik volatilite değerlerine bağll olarak hesaplanan VaR (Value-at-Risk) ve beklenen kayıp (Expected shortfall, ES) değerleri de Dolar-TL kurunun piyasa riskinin Euro-TL kuruna göre daha yüksek olduğuna işaret etmektedir.

Anahtar Kelimeler: Stokastik volatilite, Döviz piyasalarl, Volatilite dinamikleri, Piyasa riski

JEL Sinıflandırması: C11, C58, F31, G32.

An Empirical Application of an Asymmetric Stochastic Volatility Model under the Generalized Hyperbolic Skew Student's t-Distribution Assumption to the Turkish Exchange Rate Market

\section{ABSTRACT}

This study applies the recently developed asymmetric stochastic volatility model to both US Dollar-Turkish Lira and Euro-Turkish Lira exchange rate returns. The Markov chain Monte Carlo algorithm based on a Bayesian approach is used to estimate the parameters of the model. The results show that the model can adequately capture the volatility dynamics of US Dollar-Turkish Lira and Euro-Turkish Lira exchange rate returns. The return volatility of US Dollar-Turkish Lira and Euro-Turkish Lira exchange rates exhibits volatility persistence and the leverage effect. Additionally, based on the variability of volatility, the findings show that the predictability of US Dollar-Turkish Lira volatility is less than that of Euro-Turkish Lira volatility. Finally, the value-at-risk and expected shortfall calculations based on the time-varying stochastic volatility produced by the asymmetric stochastic volatility model indicate that US Dollar-Turkish Lira has a higher market risk than Euro-Turkish Lira has.

Keywords: Stochastic volatility, Exchange rate market, Volatility dynamics, Market risk

Jel Classification: C11, C58, F31, G32.

\footnotetext{
* Makale Gönderim Tarihi: 03.03.2020, Makale Kabul Tarihi: 22.06.2020, Makale Türü: Nicel Araştırma

** Doç. Dr., Yüzüncü Y1l Üniversitesi, e-posta: onderbuber@gmail.com, ORCID: 0000-0002-7140-557X.
} 


\section{GÍRIŞ}

Döviz piyasaları Türkiye gibi gelişen piyasa ekonomileri açısından oldukça önemli piyasalardır. Çünkü, Türkiye gibi sermaye açığı bulunan ve buna bağlı olarak finansal ve reel sektör kuruluşlarının bilanço içerisinde açık pozisyon ile çalıştığı ülke ekonomilerinde döviz kurlarındaki beklenmedik fiyat hareketlerinin yol açtı̆̆ 1 yüksek volatilite oldukça önemli makro ekonomik ve finansal sorunlara yol açabilmektedir. Örneğin, döviz kuru volatilitesindeki beklenmedik hareketler Türkiye'ye yatırım yapmış olan uluslararası yatırımcıların dönem sonunda ellerine geçecek döviz cinsi fon tutarını belirsiz kılarak bu ülkelere dönük fon akışını negatif bir şekilde etkileyebilmektedir (King, Osler ve Rime, 2011: 2). Bu vb. nedenlerden dolay1 döviz kuru volatilitesinin genel seyri Türkiye gibi gelişen piyasa ekonomilerindeki makro finansal risk düzeyinin temel göstergelerinden biri olarak değerlendirilebilmektedir (Başçı ve Kara, 2011: 21; Ranciere, Tornell ve Vamvakidis 2010:3). Bu nedenlerle Türkiye ekonomisi için etkin ekonomi politikalarının uygulanabilmesi ve doğru finansal yatırım kararlarının verilebilmesi için döviz kuru volatilitesinin temel dinamiklerinin iyi anlaşılmasının gerekli olduğu düşünülmektedir. $\mathrm{Bu}$ amaçla bu çalışmada Dolar-TL ve Euro-TL kurlarının volatilitesinin temel dinamikleri ve bu döviz kurlarının volatilitesinin yol açabileceği finansal risk düzeyleri literatüre Nakajima ve Omori (2012) tarafından kazandırılmış olan genelleştirilmiş hiperbolik çarpık student $\mathrm{t}$ dağılım varsayımına dayalı asimetrik stokastik volatilite modeli (GH-ASV-skw st $)^{1}$ ile incelenmiştir.

Güncel uluslararası finans literatüründe çeşitli finansal varlıkların volatilite dinamiklerinin stokastik volatilite modelleri ile incelenmesinin oldukça ilgi gördüğü bilinmektedir. (Örneğin, bakınız: Wang, 2011; Larsson ve Nossman, 2011; Ishihara ve Omori, 2012; Pan ve Li, 2013; Shirota, Hizu ve Omori, 2014; Jensen ve Maheu, 2014; Dimitrakopoulos, 2017; Lafosse ve Rodriguez, 2018). Ayrıca, oldukça sınırlı sayıda olmakla birlikte ulusal yazında da stokastik volatilite modellerine dayalı çalışmalar bulunmaktadır. (Örneğin, bakınız: Özün ve Türk, 2008; Abiyev, 2015; Göktaş ve Hepsağ, 2016). Fakat, henüz uluslararası yazında bile GH-ASV-skw st modeline dayalı sadece iki adet çalışma bulunmaktadır. Bu çalışmaların ilkinde Nakajima ve Omori (2012) GH-ASV-skw st modelini 1970-2003 dönemini dikkate alarak ABD (S\&P50) ve Japonya (TOPIX) hisse senedi piyasalarına uygulamışlardır. Hem tüm dönem için hem de çeşitli alt dönemler için GH-ASVskw st modelinin performansını standart normal dağılıma ve student $t$ dağılımına sahip stokastik volatilite modelleri ile karşılaştırdıkları çalışmalarında GH-ASV-skw st modelinin hisse senedi piyasalarının volatilite dinamiklerini modellemede diğer iki alternatif modele göre daha başarılı olduğu sonucuna ulaşmışlardır. İkinci çalışmada ise Lafosse ve Rodriguez (2018) GH-ASV-skw st modelini ABD, Şili, Meksika, Brezilya, Arjantin ve Peru hisse senedi piyasalarına uygulamışlardır. Analizler sonucunda ABD ve Arjantin hisse senedi piyasalarının getiri dağılımlarının asimetrik bir yapı sergilediği ve kalın kuyruk özelliği gösterdiği, Peru dışındaki tüm hisse senedi piyasaları için asimetrik tepkinin geçerli olduğu ve çalışmada kullanılan diğer alternatif stokastik volatilite modellerine nazaran GH-ASV-skw st modelinin inceleme kapsamındaki hisse senedi piyasalarının çoğu için daha uygun bir model olduğu sonucuna ulaşmışlardır. Dolayısıyla, ilgili her iki çalışmanın da finansal varlıkların

\footnotetext{
${ }^{1}$ GH-ASV-skw st ifadesi modelin temel özellikleri dikkate alınarak oluşturulmuş bir kısaltmadır. Daha açık bir ifadeyle burada GH, "genelleştirilmiş hiperbolik" (generalized hyperbolic); ASV, "asimetrik stokastik volatilite" (asymmetric stochastic volatility), skw st ise “çarpık student t dağılım varsayımı”nı (skew student's t-distribution assumption) ifade etmektedir.
} 
volatilitesinin modellenmesinde diğer alternatif modeller yerine GH-ASV-skw st modelinin kullanılmasının daha uygun bir yaklaşım olabileceği sonucuna ulaşıı̆ı anlaşılmaktadır. Bu nedenle bu çalışmada GH-ASV-skw st modeli Tük döviz piyasasına uygulanmıştır. Çalışmada Türk döviz piyasalarını temsilen Dolar-TL ve Euro-TL kurları kullanılmıştır.

$\mathrm{Bu}$ çalışmanın üç temel amacı bulunmaktadır. Bunlardan birincisi Bayesyen yaklaşımına dayalı MCMC algoritması kullanılarak tahmin edilen GH-ASV-skw st modelinin etkinliğinin / Türk döviz piyasalarına uygulanabilirliğinin incelenmesidir. Bu amaçla bu modeli kullanan ilgili çalı̧̧malarla uyumlu bir şekilde, model parametrelerine ait yoğunluk dağılım grafikleri (posterior densities), otokorelasyon fonksiyonları ve her bir parametre için üretilen örneklem patikasının sunduğu bulgulardan yararlanılmıştır. Çalşmanın ikinci amacı GH-ASV-skw st modelinin Türk döviz piyasasının volatilite dinamikleri konusunda sunduğu bulguların analiz edilmesidir. Çalışmanın üçüncü amacı ise GH-ASV-skw st VaR (Value-at risk, VaR) ve GH-ASV-skw st ES (Expected Shortfall, ES) modelleri aracılığı ile Dolar-TL ve Euro-TL kurlarının piyasa risklerinin hesaplanmasıdır.

Çalışmanın, literatüre çeşitli açılardan katkı sağladığı düşünülmektedir. Öncelikle, daha önce de ifade edildiği gibi uluslararası yazında bile bu modele dayalı henüz 2 adet çalışma bulunmakta ve bu her iki çalı̧̧ma da hisse senedi piyasalarını incelemektedir. Dolayısıyla, ulusal yazında ilgili model ilk defa kullanılmakta ve diğer iki çalışmadan farklı olarak model hisse senedi piyasalarına değil döviz piyasasına uygulanmaktadır. İkinci olarak, bu çalışmada sadece Dolar-TL volatilitesi değil aynı zamanda Euro-TL volatilitesi de incelenmiştir. Böylece, hem her iki döviz kurunun volatilite dinamikleri karşılaştırılabilmiş hem de Türk döviz piyasası için göreceli olarak daha kapsayıcı bir analiz yapılmaya çalışılmıştır. Üçüncüsü, bu yeni model ile hem Dolar-TL ve Euro-TL'nin volatilitesinin özellikleri konusunda yeni bulgular sunulmuş hem de her iki döviz kuru için GH-ASV-skw st modeli tarafindan üretilen zamanla değişen stokastik volatilite değerlerine bağl olarak GHASV-skw st-VaR ve GH-ASV-skw st-ES değerleri de hesaplanmıştır. Böylece, her iki döviz kurunun volatilitesinin yol açabileceği piyasa riski de analiz edilmiştir.

Çalışma dört bölümden oluşmaktadır. İkinci bölümde veri ve metodoloji sunulmakta üçüncü bölümde bulgular değerlendirilmekte son bölümde ise sonuç kısmı yer almaktadır.

\section{VERİ VE METODOLOJİ}

\subsection{Veri}

Çalışma, 1 Ocak 2002 ile 18 Mayıs 2010 dönemini kapsamakta ve günlük verilerden oluşmaktadır. Çalışmanın başlangıç yılının 2002 yılı olmasının temel nedeni Türkiye ekonomisinin 2001 yılının Şubat ayında önemli bir finansal kriz ile karşs karşıya kalmış olması ve bu krizin hemen ardından başta para politikası uygulamaları ve kur rejimi olmak üzere çeşitli alanlarda önemli yapısal dönüşümler yaşanmış olmasıdır. Çalışmanın 2010 yılının Mayıs ayında son bulması ise bu dönem ile birlikte merkez bankasının geleneksel para politikası uygulamaların terk edip geleneksel olmayan para politikas1 uygulamalarına geçmiş olmasından kaynaklanmaktadır (Küçük vd., 2013:8). Bir diğer ifade ile merkez bankası ABD merkezli olarak başlayan 2007-2008 küresel finans krizinin bir sonucu olarak 2010 yılının Mayıs ayı ile birlikte geleneksel olmayan para politikas1 uygulamalarını esas almış ve bunun bir uzantısı olarak bu yeni uygulamada döviz kurlarını bir 
ara değişken olarak tanımlamıştır. Ayrıca, merkez bankası "tek araç tek hedef" politikasından “çoklu araç çoklu hedef” politikasına geçmiştir. Dolayısıyla, 18 Mayıs 2010 tarihi ile birlikte merkez bankasının (döviz kurlarını da ara değişken olarak tanımlayarak) oldukça farklı bir para politikası uygulamasına geçmiş olması nedeniyle bu dönemin dinamiklerinin ayrıca incelenmesi gerektiği düşünülmektedir² .

Çalışmadaki tüm veriler TCMB Elektronik Veri Dağıtım Sistemi’nden alınmıştır. Türk döviz piyasalarını temsilen Dolar-TL ve Euro-TL kurları kullanılmıştır. Günlük logaritmik getiri serileri $\left(r_{t}\right)$ Denklem (1)'de gösterildiği gibi hesaplanmıştır:

$$
r_{t}=\left[\ln P_{t}-\ln P_{t-1}\right]
$$

Burada, $\ln P_{t}$ ilgili döviz kurlarının $t$ zamanındaki kapanış değerlerinin logaritmasını göstermektedir.

\subsection{Metodoloji}

Nakajima ve Omori (2012) tarafindan geliştirilen GH-ASV-skw st modeli Denklem (2), (3), (4) ve (5)'te gösterilmiştir.

$$
\begin{aligned}
& y_{t}=\exp \left(\frac{h_{t}}{2}\right) \beta\left\{\left(z_{t}-\mu_{z}\right)+\sqrt{z_{t}} \epsilon_{t}\right\}, t=1,2, \ldots \ldots, T \\
& h_{t+1}=\mu+\phi\left(h_{t}-\mu\right)+\eta_{t}, t=1,2, \ldots . T-1 \\
& z_{t} \sim I G\left(\frac{v}{2}, \frac{v}{2}\right), \\
& \left(\begin{array}{l}
\epsilon_{t} \\
\eta_{t}
\end{array}\right) \sim N\left(0, \sum\right), \quad \text { ve } \Sigma=\left(\begin{array}{cc}
1 & \rho \sigma \\
\rho \sigma & \sigma^{2}
\end{array}\right),
\end{aligned}
$$

Burada, Denklem (2) gözlem (observation) denklemini Denklem (3) ise dönüşüm ( translation) denklemini ifade etmekte ve $y_{t}$ ilgili finansal varlığın logaritmik getirisini; $h_{t}$ ilgili finansal varlığın getirisinin gözlemlenemeyen logaritmik volatilite değerini, $\phi$ volatilite kalıcılığ1 parametresini, $\mu$ logaritmik volatilitenin şartsız (unconditional) ortalama değerini; $\epsilon_{t}$ ve $\eta_{t}$ sirasıyla gözlem ve dönüşüm denklemlerinin tesadüfi hata terimlerini; $\rho$ asimetri parametresini; $\sigma^{2}$ logaritmik volatilitenin değişkenliğini bir diğer ifade ile logaritmik volatilitenin volatilitesini; $z_{t}$ gözlemlenemeyen (latent) değişkeni; IG ters (inverse) Gamma

\footnotetext{
2 Ayrıca, geleneksel olmayan para politikası uygulamalının geçerli olduğu dönem için elde edilecek bulguların bu çalışma kapsamındaki bulgular ile karşılaştırılmasının merkez bankası politikalarının başarısı ve Türk döviz piyasalarının volatilite dinamiklerinin daha iyi anlaşlabilmesi açısından oldukça önemli olabileceği düşünülmektedir.
} 
dağılımını, $v ; \quad v>4$ olacak şekilde serbestlik derecesini, $\beta$ ise çarpıklık parametresini göstermektedir.

Çalışmada, GH-ASV-skw st modeli literatürle uyumlu bir şekilde Bayesyen yaklaşımına dayalı olarak MCMC algoritması ile tahmin edilmiş ve Nakajima ve Omori (2012) ile Lafosse ve Rodriguez'in (2018) çalışmalarında olduğu gibi model parametreleri için Tablo 1 ve 2'de gösterilen başlangıç değerlerinden ve dağılım varsayımlarından (prior distributions) yararlanılmıştır.

Tablo 1. GH-ASV-skw st Model Parametreleri için Kullanılan Başlangıç Değerleri

\begin{tabular}{|l|l|}
\hline Parametreler & Başlangıç değerleri \\
\hline$\phi$ & 0,95 \\
\hline$\sigma$ & 0,15 \\
\hline$\mu$ & -9 \\
\hline$\beta$ & $-0,5$ \\
\hline$v$ & 15 \\
\hline
\end{tabular}

Tablo 2. GH-ASV-sktw st Model Parametreleri için Kullanılan (Prior distributions) Dağılım Varsayımları

\begin{tabular}{|l|l|l|}
\hline Parametreler & Dağılım varsayımı & Dağılım parametrelerinin tanımlanması \\
\hline$(\phi+1) / 2$ & Beta dağılımı & $\sim$ Beta $(20 ; 1,5)$ \\
\hline$\sigma^{2}$ & Ters gamma dağılımı & $\sim$ Ters-Gamma $(2,5 ; 0,025)$ \\
\hline$\rho$ & Üniform dağılım & $\sim \mathrm{U}(-1,1)$ \\
\hline$\mu$ & Normal dağılım & $\sim \mathrm{N}(-10,1)$ \\
\hline$\beta$ & Standart normal dağılım & $\sim \mathrm{N}(0,1)$ \\
\hline$v$ & Gamma dağ 1 lımı & $\sim \operatorname{Gamma}(16 ; 0,8) । v>4$ \\
\hline
\end{tabular}

Asimetri $(\rho)$ parametresinin başlangıç değeri ise Nakajima ve Omori (2007) ile Lafosse ve Rodriguez'in (2018) çalışmalarından farklı olarak Selçuk'un (2004) çalışmasında olduğu gibi 0,50 olarak alınmıştır. Bunun nedeni ise şudur: Nakajima ve Omori (2012) ile Lafosse ve Rodriguez'in (2018) çalışmalarında GH-ASV-skw-st modeli hisse senedi piyasalarına uygulanmıştır. Bu her iki çalışmada da literatürdeki genel uygulama takip edilerek hisse senedi piyasalarına ASV modelleri uygulanırken asimetri parametresi negatif bir değer olarak tanımlanmıştır. Bu durum ise finans teorilerine bağlı olarak hisse senedi getirilerindeki değişimler ile hisse senedi volatilitesi arasındaki ilişkinin ters yönlü olmasından kaynaklanmaktadır. Bu çalışmada ise GH-ASV-skw st modeli yapısal olarak cari açık veren gelişen bir ülkenin döviz piyasasına uygulanmıştır ve teorik olarak bu tür bir gelişen piyasa ekonomisinin döviz piyasalarındaki asimetrik tepkinin işaretinin pozitif olması beklenmektedir. Çünkü, Selçuk'un (2004:696) ifade ettiği gibi döviz cinsinden önemli oranda diş borcu bulunan gelişen piyasa ekonomilerinde yerel para birimlerinin değer kaybetmesi bu ülkelerin dış borç stokunun artmasına sebep olmaktadır. Değer kaybı arttıkça da bu ülke ekonomileri için risk daha da arttığından volatilite de giderek artmaktadır. $\mathrm{Bu}$ nedenle sermaye açığ 1 bulunan ve yapısal olarak cari açık veren gelişen ülke para birimleri için asimetri parametresinin pozitif bir değer olarak tanımlanması gerekmektedir.

Çalışmada, GH-ASV-skw st modeli tahmin edildikten sonra Dolar-TL ve Euro-TL kurları için elde edilen zamanla değişen stokastik volatilite değerlerine bağlı olarak 
yatırımcıların Dolar-TL ve Euro-TL kurlarında uzun pozisyon taşımaları durumunda karşı karşıya kalabilecekleri finansal risk düzeyleri GH-ASV-skw st-VaR ve GH-ASV-skw-st- ES değerleri ile ölçülmüştür. GH-ASV-skw st-VaR değeri Denklem (6)'da gösterildiği gibi hesaplanmıştır:

$$
V a R_{t+1}=\mu_{t}+z_{\sigma} h_{t}
$$

Burada, $\quad \mu_{t} ;$ şartlı ortalama getiriyi, $z_{\varpi} ;$ GH-skw st dağılımının kritik tablo değerini; $h_{t}$ ise şartlı stokastik volatilite değerini ifade etmektedir. GH-ASV-skw st-ES değerleri de Denklem (6) esas alınarak hesaplanan GH-ASV-skw-st-VaR modelinin sunduğu kayıp tutarı ile bu tutarını aşan kayıp tutarlarının ortalaması alınarak hesaplanmaktadır.

\section{BULGULAR}

Çalışmanın bu aşamasında öncelikle değişkenlere ait temel istatistiki veriler sunulmuştur. Ardından, GH-ASV-skw st modelinin Türk döviz piyasalarına uygulanabilirliği ile ilgili analizlere yer verilmiştir. Daha sonra, GH-ASV-skw st modelinin Dolar-TL ve EuroTL kurlarının volatilite dinamikleri konusunda sunduğu bulgular değerlendirilmiştir. Son olarak da GH-ASV-skw-st-VaR ve GH-ASV-skw st-ES modelleri kullanılarak Dolar-TL ve Euro-TL kurlarının finansal risk düzeyleri hesaplanmıştır.

\subsection{Değişkenlere Ait Temel İstatistiki Veriler}

Çalışma kapsamında kullanılan Dolar-TL ve Euro-TL kurlarının Denklem (1) kapsamında elde edilen logaritmik getiri serileri Şekil 1'de, bu getiri serilerine ait betimleyici istatistikler ile birim kök ve değişen varyans testi sonuçları ise Tablo 3 'te sunulmuştur.

DOLAR

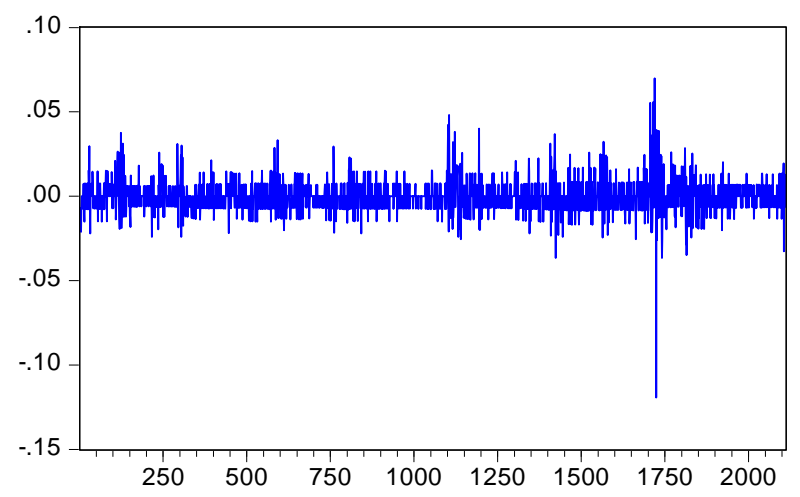

EURO

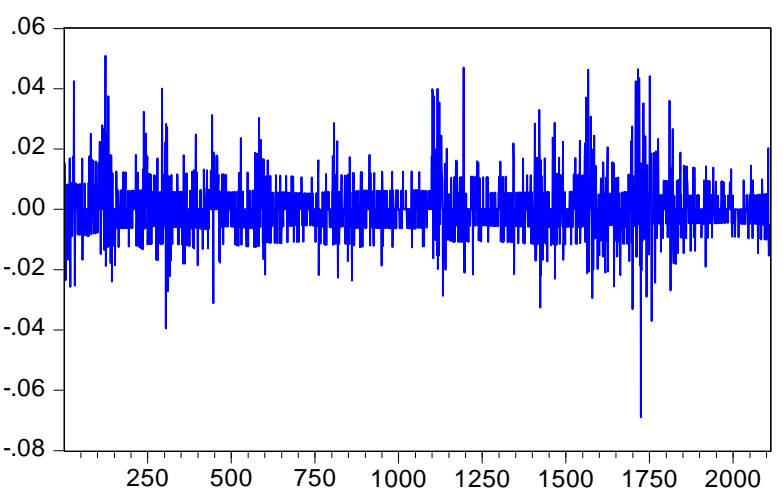

Şekil 1. İlgili Dönem için Hesaplanan Logaritmik Dolar-TL ve Euro-TL Getirileri Ayrıca, getiri serilerinin dağılım özelliklerinin analiz edilebilmesi için Tablo 3 'te sunulan basıklık / çarpıklık değerleri ile Jarque-Bera testi sonuçlarına ilaveten, Şekil 2 ve 3'te Q-Q grafiklerine de yer verilmiştir. Burada getiri serilerinin dağılım özellikleri üzerinde durulmasının temel nedeni ise literatürde sıklıkla kullanılan standart normal dağılım ve 
student $\mathrm{t}$ dağılımının Dolar-TL ve Euro-TL getirileri için uygun birer dağılım varsayımı olmayabileceğini gösterebilmektir. Çünkü, bu tür bir bulgunun bu çalışmada kullanılan genelleştirilmiş hiperbolik çarpık student $t$ dağılım varsayımının önemini daha da arttırabileceği düşünülmektedir.

Bu kapsamda, öncelikle Tablo 3'teki bulgular incelendiğinde hem Dolar-TL hem de Euro-TL getirilerinin durağan olduğu, çok düşük bir değer olmakla birlikte her iki döviz kurunun da pozitif bir ortalama getiri sunduğu ve her iki döviz kurunun standart sapma değerlerine dayalı toplam riskinin birbirine oldukça yakın olduğu anlaşılmaktadır. ARCH testi sonuçları da döviz kuru getirilerinin değişen varyans sorunu içerdiğini göstermektedir. Bu bulgular Dolar-TL ve Euro-TL getirilerinin volatilitesinin modellenmesinde stokastik volatilite modelleri gibi değişen varyans özelliğini dikkate alabilen modellerin kullanılabileceği anlamına gelmektedir. Dağılım varsayımına gelince, öncelikle Jarque-Bera testi sonuçlarına bakıldığında her iki döviz kuru getirisinin de standart normal dağılıma uymadığı anlaşılmaktadır (Tablo 3).

Tablo 3. Döviz Kuru Getirilerine İlişkin Betimleyici İstatistikler, Birim Kök ve Değişen Varyans Testi Sonuçları (\%)

\begin{tabular}{|l|l|l|}
\hline & Dolar-TL & Euro-TL \\
\hline Birim kök testleri & & \\
\hline ADF & $-10,6328^{*}[0,0000]$ & $-34,0246 *[0,0000]$ \\
\hline PP & $-46,3091^{*}[0,0001]$ & $-46,5244 *[0,0000]$ \\
\hline Betimleyici istatistikler & & \\
\hline Ortalama & 0,00285 & 0,01852 \\
\hline Std. Sapma & 0,9864 & 0,9721 \\
\hline Çarp1klk & $-0,07074$ & 0,51918 \\
\hline Basıklk & 16,3243 & 7,0008 \\
\hline Jarque Bera & $0,0000^{*}$ & $0,0000 *$ \\
\hline ARCH (2) & $21,738^{*}[0,0000]$ & $25,452 *[0,0000]$ \\
\hline ARCH (12) & $25,983 *[0,0000]$ & $16,961 *[0,0000]$ \\
\hline
\end{tabular}

*, \%5 anlamlılık düzeyini göstermektedir. Jarque-Bera test istatistiği için verilen değerler olasılık değerleridir. Birim kök testleri trendsiz model spesifikasyonu dikkate alınarak uygulanmıştır. Birim kök ve ARCH testleri için köşeli parantez içerisinde verilen değerler olasılık değerleridir. ADF, Augmented Dickey-Fuller; PP ise Phillips-Perron birim kök testini ifade etmektedir.

Şekil 2'de sunulan Q-Q grafiklerine bakıldığında da Jargue-Bera testi ile benzer sonuçlara ulaşıldığı anlaşılmaktadır. 


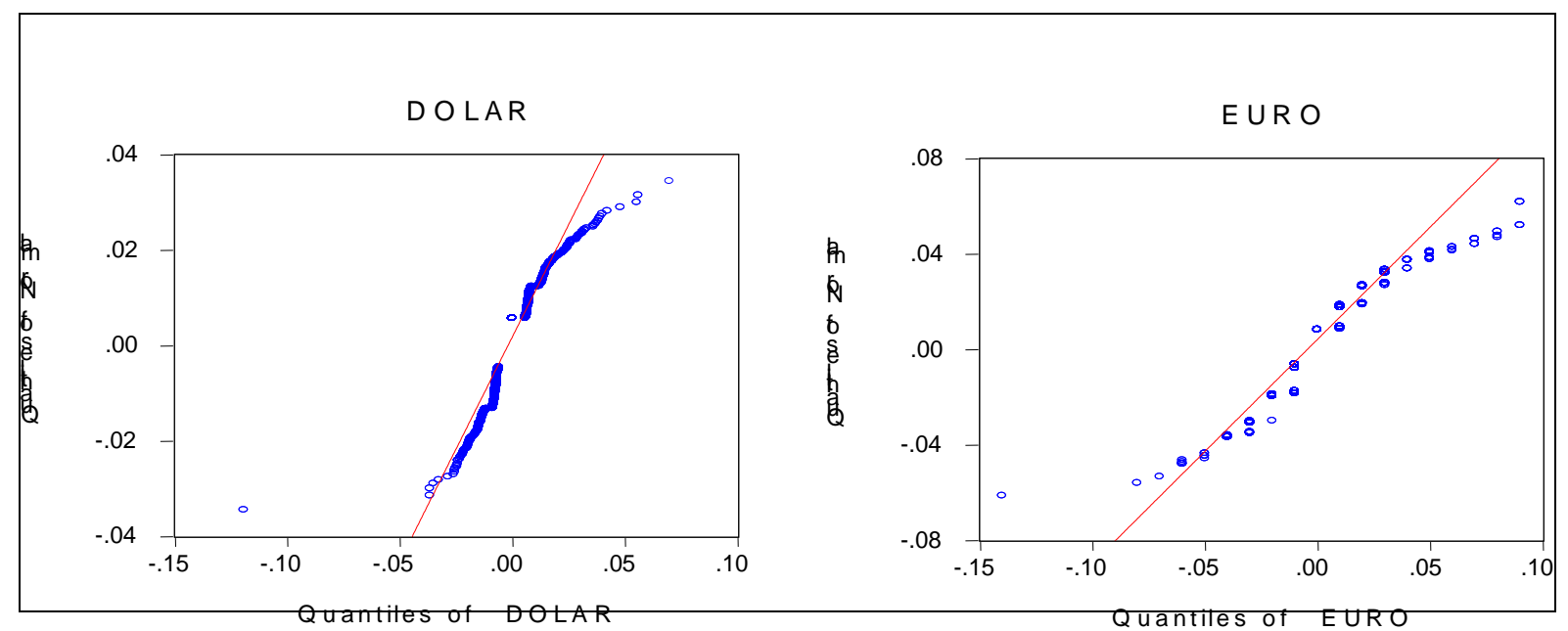

Not: Getiri serilerinin standart normal dağılıma uyduğu sonucuna ulaşılabilmesi için mavi renkle gösterilen değerlerin, kırmızı renkle gösterilen çizginin tamamen üzerinde yer alması gerekmektedir.

Şekil 2. Dolar-TL ve Euro-TL Getirileri için Q-Q Grafikleri (Standart normal dağılım)

Ayrıca, Şekil 3'te gösterilen ve getiri serilerine student $\mathrm{t}$ dağılım varsayımı dikkate alınarak uygulanan Q-Q grafiklerinin döviz kuru getirilerinin student $t$ dağılım varsayımına da uymadığı sonucuna işaret ettiği anlaşılmaktadır.
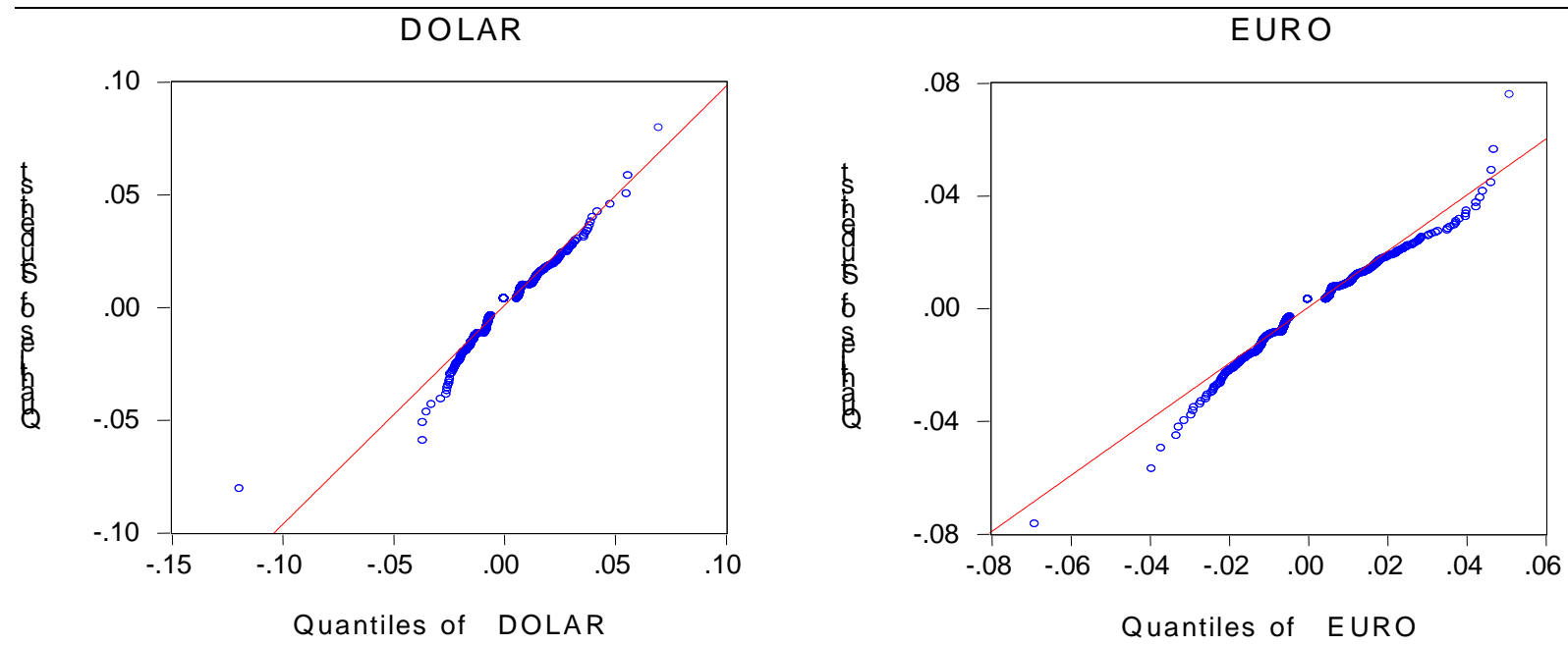

Not: Getiri serilerinin standart normal dağılıma uyduğu sonucuna ulaşılabilmesi için mavi renkle gösterilen değerlerin, kırmızı renkle gösterilen çizginin tamamen üzerinde yer alması gerekmektedir.

Şekil 3. Dolar-TL ve Euro-TL Getirileri için Q-Q Grafikleri (Student t dağılımı) 
Bunun yanı sıra Tablo 3'te sunulan bulgular her iki döviz kuru getirisinin çarpık bir dağılıma sahip olduğu ve kalın kuyruk özelliği sergilediği sonucuna işaret etmektedir. Bu nedenlerle stokastik volatilite modelinin standart normal dağ 11 เm ve / veya student $t$ dağılımı gibi geleneksel dağılım varsayımları dışında, bu çalışmada olduğu gibi genelleştirilmiş hiperbolik çarpık student $t$ dağılım varsayımı gibi alternatif dağılım varsayımları ile tahmin edilebileceği anlaşılmaktadır.

\subsection{Bayesyen Yaklaşımına dayalı MCMC Algoritması Kullanılarak Tahmin Edilen GH-ASV-skw st Modelinin Etkinliğinin Analizi}

Çalışmanın bu aşamasında GH-ASV-skw st modelinin Dolar-TL ve Euro-TL kurlarına etkin bir şekilde uygulanıp uygulanamayacağı analiz edilecektir. Literatürde bu amaçla her bir parametreye ilişkin yoğunluk dağılım grafikleri (posterior densities), otokorelasyon fonksiyonları ve her bir parametre için üretilen ve 20.000 değerden oluşan örneklem patikasının genel seyri değerlendirilmektedir. $\mathrm{Bu}$ çalışmada da benzer bir analiz yapılmış ve elde edilen bulgular Şekil 4'te sunulmuştur. Şekil 4 incelendiğinde her bir parametre için otokorelasyon fonksiyonunun hizlıca azaldığ 1 ve parametrelerin aldığ değerlerin (örneklem patikasının) göreceli olarak istikrarlı bir seyir izlediği anlaşılmaktadır. Bu bulgular da MCMC algoritmasının etkin örneklem değerleri ürettiği anlamına gelmektedir (Nakajima ve Omori, 2009: 2339). Dolayısıyla, Bayesyen yaklaşımına dayalı MCMC algoritması ile tahmin edilen GH-ASV-skw st modelinin Türk döviz piyasalarına uygulanabileceği ifade edilebilir.

Şekil 4. Dolar-TL ve Euro-TL için Otokorelasyon, Örneklem Patikası ve Parametre Yoğunluk Dağılımı
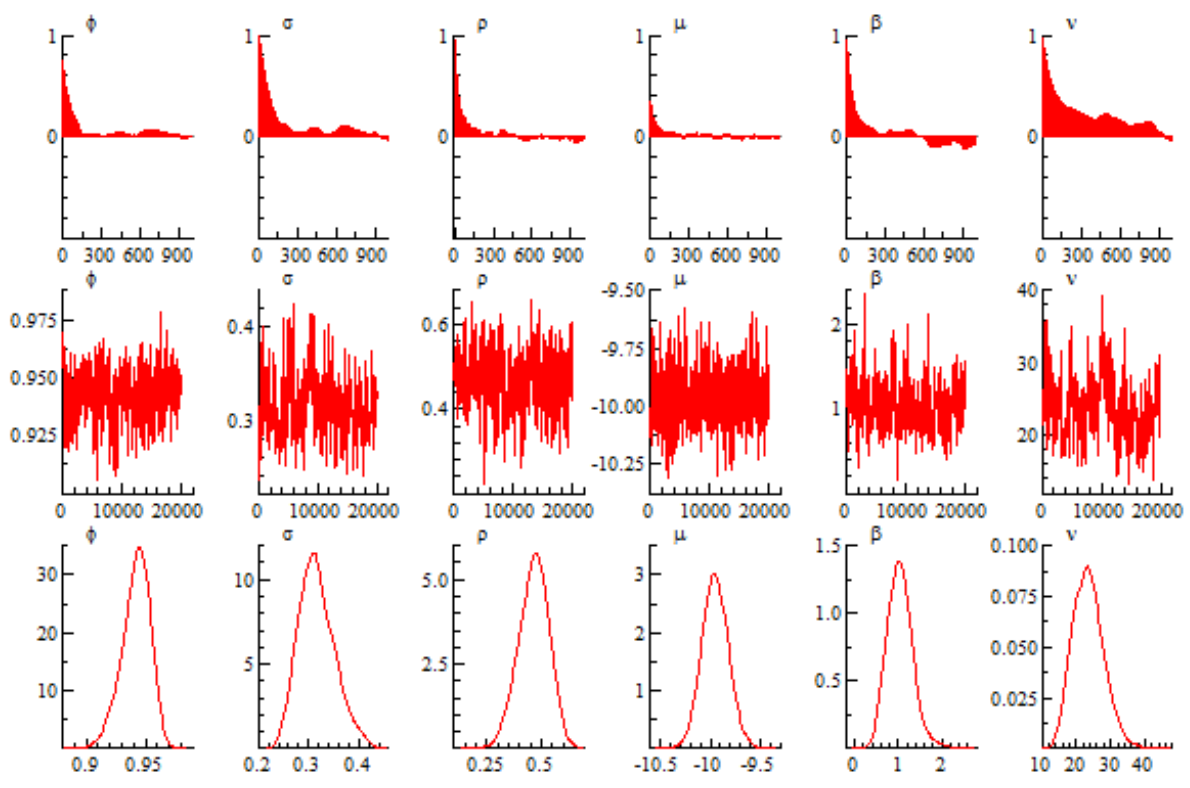

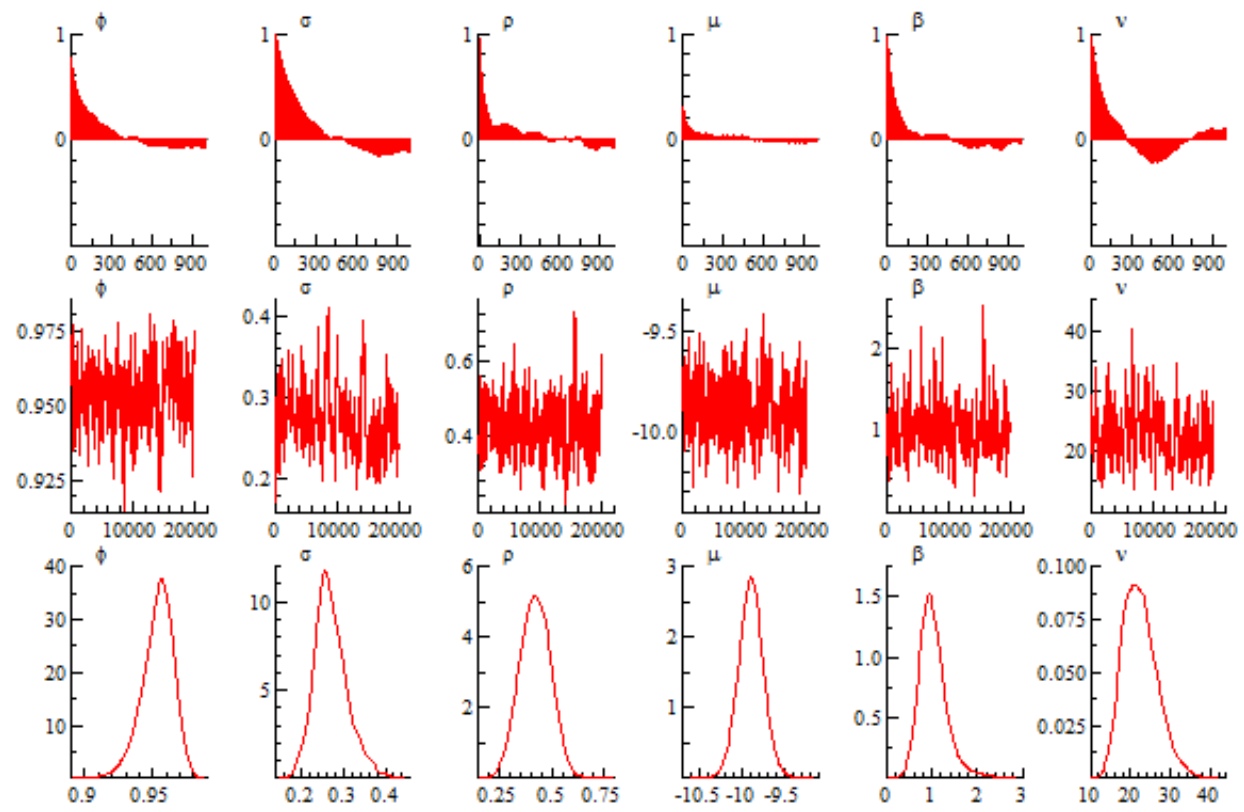

Not: Her iki durumda da birinci sıradaki grafikler otokorelasyon fonksiyonunu, ikinci sıradaki grafikler örneklem patikasını, üçüncü sıradaki grafikler ise parametre yoğunluk dağılımını göstermektedir.

\subsection{GH-ASV-skw-st Modeli Kapsamında Döviz Piyasasının Volatilite Dinamiklerinin İncelenmesi}

Çalışmanın bu aşamasında GH-ASV-skw st modelinin parametreleri tahmin edilmiş ve bu parametrelerin Türk döviz piyasasının volatilite dinamikleri konusunda sunduğu bulgular değerlendirilmiştir. Bu kapsamda elde edilen sonuçlar Tablo 4'te sunulmuştur ${ }^{3}$.

Tablo 4. GH-ASV-skw-st Modelinin Tahmin Sonuçları

\begin{tabular}{|c|c|c|c|c|c|}
\hline Parametreler & Ortalama & Std.sapma & $\% 95$ alt sinır & \%95 üst sınır & Etkinsizlik faktörü \\
\hline \multicolumn{6}{|l|}{ Dolar-TL } \\
\hline$\phi$ & 0,9421 & 0,0120 & 0,9158 & 0,9625 & 87,64 \\
\hline$\sigma$ & 0,3168 & 0,0358 & 0,2549 & 0,3960 & 172,03 \\
\hline$\rho$ & 0,4657 & 0,0695 & 0,3219 & 0,5925 & 86,57 \\
\hline$\mu$ & $-9,9507$ & 0,1325 & $-10,2055$ & $-9,6860$ & 33,16 \\
\hline$\beta$ & 1,0442 & 0,3002 & 0,5196 & 1,7001 & 114,91 \\
\hline v & 23,565 & 4,4756 & 15,8230 & 32,9691 & 264,58 \\
\hline \multicolumn{6}{|l|}{ Euro-TL } \\
\hline$\phi$ & 0,9537 & 0,0115 & 0,9275 & 0,9733 & 147,97 \\
\hline$\sigma$ & 0,2724 & 0,0387 & 0,2042 & 0,3621 & 242,70 \\
\hline$p$ & 0,4205 & 0,0745 & 0,2778 & 0,5618 & 116,11 \\
\hline$\mu$ & $-9,8971$ & 0,1454 & $-10,1832$ & $-9,6087$ & 37,49 \\
\hline$\beta$ & 1,0269 & 0,3117 & 0,5276 & 1,7958 & 119,10 \\
\hline v & 22,4218 & 4,2494 & 15,3042 & 31,8477 & 135,01 \\
\hline
\end{tabular}

Tabloda her bir parametre için verilen ortalama değerler (posterior means) her bir parametre için üretilen ve Şekil 4’teki örneklem patikasında gösterilen 20.000 değerin ortalamasını ifade etmektedir.

3 Her bir döviz kuru için GH-ASV-skw st modelinin tahmin edilmesi yaklaşık 18 saat sürmektedir. Bu nedenle tüm model parametrelerinin tahmini yaklaşık 36 saat sürmüştür. 
Sonuçlar incelendiğinde öncelikle hem Dolar-TL hem de Euro-TL için \%95 güven düzeyinde (credibility interval) tüm parametrelerin istatistiki olarak anlamlı olduğu anlaşılmaktadır. Çünkü, tüm parametrelerin ortalama değerleri (posterior means) \% 95 güven düzeyinin alt ve üst sınırları arasında yer almakta ve hiç bir parametre için \%95 güven düzeyinin alt ve üst sınırları arasında sıfır değeri bulunmamaktadır (Berumet, Yalçın ve Yıldırım, 2011: 297). Parametrelerin Dolar-TL ve Euro-TL kurlarının volatilite dinamikleri konusunda sunduğu bulgulara gelince, her iki döviz kuru için de yüksek volatilite kalıcılığının ve asimetrik tepkinin geçerli olduğu anlaşılmaktadır. Volatilite kalıcılığı parametresinin değerinin yüksek çıkması hem Dolar-TL hem de Euro-TL için t-1 dönemindeki bir volatilite şokunun $t$ dönemindeki volatilite üzerinde uzun süre etkili olabileceği anlamına gelmektedir. Ayrıca, bu etkinin Euro-TL için biraz daha fazla olduğu anlaşılmaktadır. Çünkü, volatilite kalıcılığı parametresinin ortalama değeri (posterior mean) Euro-TL kuru için daha yüksek çıkmaktadır. Fakat, her iki döviz kuru için de volatilite kalıcılığı parametresinin 1 'den küçük değerler alması durağanlık koşulunun sağlandığı dolayısıyla t-1 döneminde yaşanan bir volatilite şokunun sistem üzerindeki etkisinin belli bir süre sonra kendi kendine sistem dişına çıkabileceği anlamına gelmektedir. Asimetri parametresinin pozitif ve istatistiki olarak anlamlı çıkması ise Dolar-TL ve Euro-TL getirilerindeki artışların (Doların ve Euronun TL karşısında değer kazanmasının) Dolar-TL ve Euro-TL volatilitesini artırdığ 1 , Dolar-TL ve Euro-TL getirisindeki azalışların (Doların ve Euronun TL karşısında değer kaybetmesinin) ise Dolar-TL ve Euro-TL volatilitesini azalttığ 1 , fakat getiri oranlarındaki artışların volatiliteyi artırıcı etkisinin getiri oranlarındaki aynı büyüklükteki azalışların volatiliteyi azaltıcı etkisinden daha fazla olduğu anlamına gelmektedir. Ayrıca, Dolar-TL getirisi ile Dolar-TL volatilitesi arasındaki asimetrik ilişkinin Euro-TL'ye göre daha güçlü olduğu anlaşılmaktadır. Çünkü, asimetri parametresi Dolar-TL kuru için daha yüksek çıkmaktadır.

Volatilite değişkenliği parametresine bakıldığında ise bu parametrenin Dolar-TL kuru için daha yüksek bir değer aldığı gözlemlenmektedir. Bu da Dolar-TL volatilitesindeki değişkenliğin daha yüksek olduğu anlamına gelmektedir. Bir diğer ifade ile Dolar-TL volatilitesinin öngörülebilirliğinin Euro-TL volatilitesine göre daha zor olduğu ifade edilebilir. Dağılım parametrelerine gelince her iki para birimi için de $\beta$ katsayısının ortalama değeri (posterior mean) pozitif çıkmaktadır. Bu da her iki döviz kuru getirisinin sağa çarpık olduğu anlamına gelmektedir. Dolayısıyla, her iki para biriminin de pozitif getiri sunma olasılıklarının negatif getiri sunma olasılıklarından daha fazla olduğu ifade edilebilir. $v$ parametresine bakıldığında da ilgili parametrenin Euro-TL için daha düşük çıktığ anlaşılmaktadır. Bu durum Euro-TL getirisinin dağılımının Dolar-TL getirisinin dağılımına göre daha belirgin bir kalın kuyruk (heavy-tail) özelliği sergilediği anlamına gelmektedir.

Belirtilen bu bulgulara ilaveten burada dikkat edilmesi gereken bazı hususlar da bulunmaktadır. Bunlardan birincisi $\beta$ katsayısıdır. Çünkü, Tablo 1'de parametrelerin başlangıç değerleri belirlenirken beta katsayısı negatif bir değer olarak tanımlanmıştı. Beta katsayısının negatif bir diğer olarak tanımlanması finansal varlıkların getiri dağılımının sola çarpık olduğu varsayımına dayanmaktadır. Nakajima ve Omori (2012) ile Lafosse ve Rodriguez (2018) çalışmalarında hisse senedi piyasalarını incelediklerinden beta katsayısını negatif bir değer olarak tanımlamışlardır. Fakat, bu model ilk defa döviz kurlarına uygulandığında beta katsayısının pozitif çıktığı gözlemlenmiştir. Bunun, Türkiye gibi gelişen bir piyasa ekonomisinin para biriminin Dolar ve Euro karşısında sistematik bir şekilde değer kaybetmesinden kaynaklandığı düşünülmektedir. $\mathrm{Bu}$ nedenle, Türkiye gibi 
yapısal olarak cari açık veren gelişen piyasa ekonomileri için daha sonra yapılabilecek çeşitli çalışmalarda beta katsayısının başlangıç değerinin pozitif bir değer olarak belirlenmesinin daha uygun bir yaklaşım olabileceği düşünülmektedir.

İkinci bir husus ise Tablo 4'te sunulan etkinsizlik faktörünün (inefficiency factor) aldığ 1 değerlerle ilgilidir. Etkinsizlik faktörünün iki temel işlevi bulunmaktadır. Bunlardan birincisi model tahmininde kullanılan algoritmalara dayalı olarak her bir parametrenin diğer parametrelere göre ne kadar etkin bir şekilde tahmin edildiğinin belirlenebilmesini sağlaması, ikincisi ise ilgili modelin daha farklı bir yaklaşımla / algoritma ile tahmin edilmesi durumunda elde edilecek yeni parametrelerin etkinliğini bu çalışmada kullanılan yaklaşımın / algoritmanın etkinliğini ile karşılaştırma imkanı sunmasıdır. Bu çalışma kapsamında, her bir parametre için etkinsizlik faktörleri incelendiğinde $v$ parametresi dişındaki tüm parametrelerde etkinsizlik faktörünün Dolar-TL için daha düşük çıktığı anlaşılmaktadır. Dolayısıyla, Euro-TL'ye göre Dolar-TL için tahmin edilen parametrelerin göreceli olarak daha etkin tahminciler oldukları ifade edilebilir. Ayrıca, ilgili tüm parametreler arasında etkinsizlik düzeyi en düşük parametrenin $\mu$ parametresi olduğu anlaşılmaktadır.

GH-ASV-skw st modeline bağlı olarak her iki döviz kuru için incelenen tüm dönem kapsamında elde edilen zamanla değişen logaritmik stokastik volatilite değerleri getiri serileri ile birlikte Şekil 5 ve 6'da sunulmuştur. Bulgular, her iki döviz kurunun hem getiri hem de volatilite değerlerinin genel seyrinin birbirine benzer olduğuna işaret etmektedir. Ayrıca, her iki döviz kurunun volatilitesinin kendi uzun dönemli denge değerine dönme eğilimi içerisinde olduğu anlaşılmaktadır. Bunun yanı sıra stokastik volatilite modelleri volatilitenin piyasaya dönük bilgi akışının bir sonucu olarak oluştuğunu varsaydığından, Dolar-TL ve Euro-TL volatilitesinin Şekil 5 ve 6'da sunulan genel seyri piyasaya hangi dönemde gelen bilgi akışının volatilite üzerinde daha fazla etkili olduğu konusunda da fikir vermektedir (Krichene, 2003: 3).

Şekil 5. Dolar-TL için Getiri ve Logaritmik Volatilite Serileri

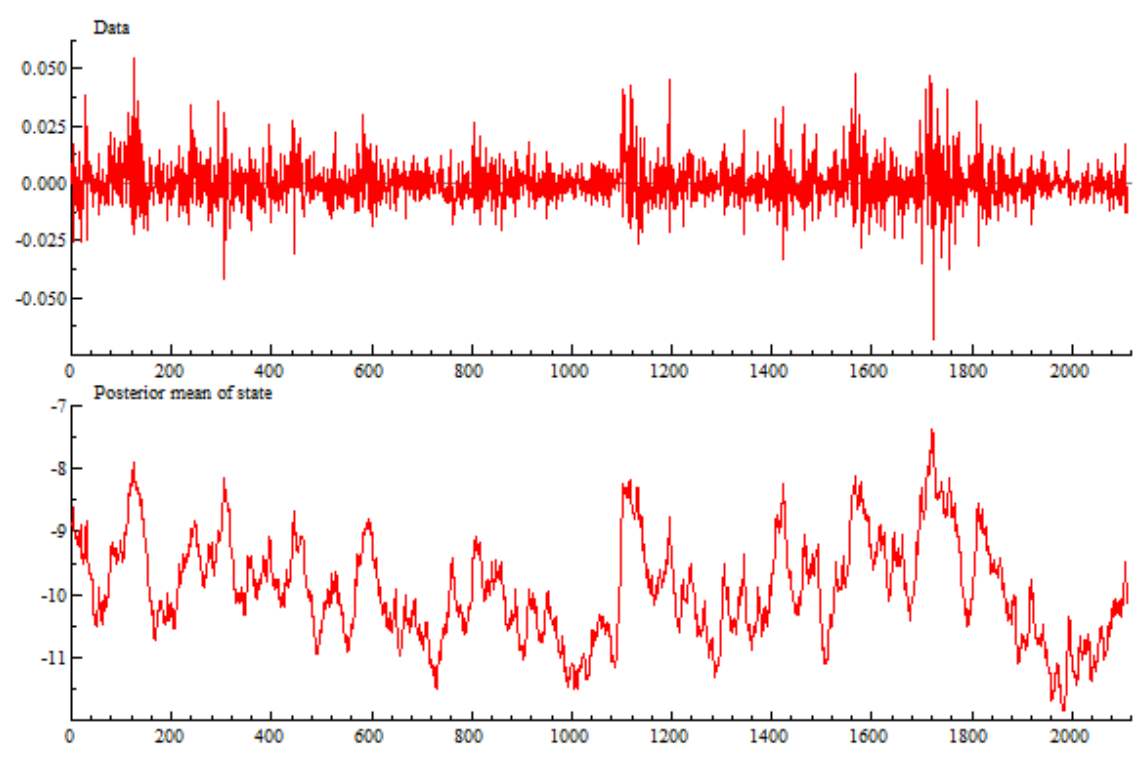




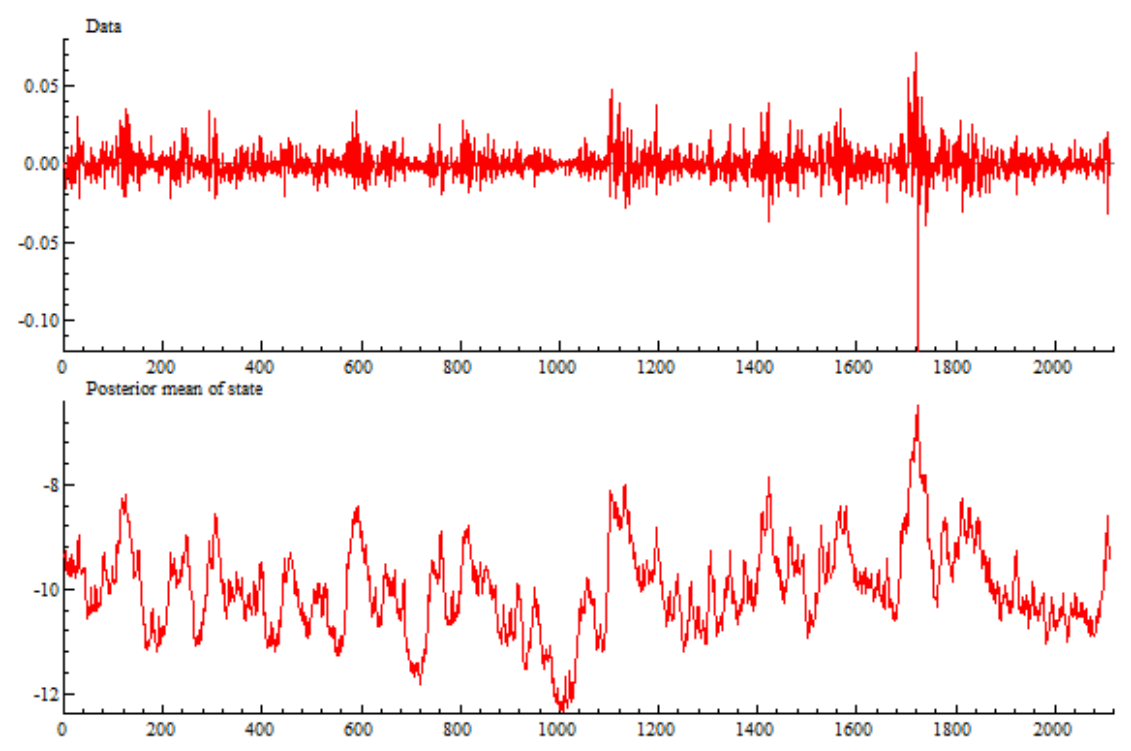

Şekil 6. Euro-TL için Getiri ve Logaritmik Volatilite Serileri

\section{Ölçümü}

3.4. GH-ASV-skw st Modeli ile Dolar-TL ve Euro-TL Kurlarının Piyasa Riskinin

Bundan önceki aşamada GH-ASV-skw st modelinin Dolar-TL ve Euro-TL kurlarının volatilite dinamikleri konusunda sunduğu bulgular yorumlanmıştı. Çalışmanın bu aşamasında ise doğrudan uygulamaya dönük sonuçlara ulaşabilmek amacıyla bu parametrelere bağlı olarak hesaplanan stokastik volatilitenin yol açabileceği piyasa riski üzerinde durulmuştur. Böylece, ilgili döviz kurlarında yatırımcılar ve / veya finansal kuruluşlarca taşınabilecek uzun pozisyonların yol açabileceği maksimum kayıp tutarları hesaplanmıştır. Bu kapsamdaki bulgular Tablo 5 'te sunulmuştur.

Tablo 5. Dolar-TL ve Euro-TL için GH-ASV- skw st-VaR ve GH-ASV-skw st-ES Sonuçları

\begin{tabular}{|c|c|c|c|}
\hline & \multicolumn{3}{|c|}{ Güven düzeyleri } \\
\hline & $\% 99,5$ & $\% 99$ & $\% 95$ \\
\hline \multicolumn{4}{|l|}{ Dolar-TL } \\
\hline GH-ASV-skw st-VaR & $-\% 3,117$ & $-\% 2,730$ & $-\% 1,781$ \\
\hline GH-ASV-skw st-ES & $-\% 3,766$ & $-\% 3,335$ & $-\% 2,372$ \\
\hline \multicolumn{4}{|l|}{ Euro-TL } \\
\hline GH-ASV-skw st-VaR & $-\% 2,159$ & $-\% 1,827$ & $-\% 1,144$ \\
\hline GH-ASV-skw st-ES & $-\% 2,547$ & $-\% 2,255$ & $-\% 1,568$ \\
\hline
\end{tabular}

Öncelikle Dolar-TL için GH-ASV-skw st-VaR sonuçları incelendiğinde, bu döviz kuruna dayalı yatırımlardan dolayı \%99 güven düzeyinde bir gün sonraki maksimum kayıp oranının \%2,73 olabileceği anlaşılmaktadır. Bir diğer ifadeyle bir yatırımcının Dolar-TL'ye $1.000 \mathrm{TL}$ yatırım yapması durumunda $\% 99$ güvenle bu yatırımından dolayı yatırımcının bir 
gün sonraki kaybının maksimum 27,3 TL (1.000 TL * \%2,73=27,3 TL) olabileceği anlaşılmaktadır. GH-ASV-skw-st-ES sonuçlarına bakıldığında ise \%1'lik hata payının gerçekleşmesi durumunda kayıp oranının \%3,335 seviyesine çıkabileceği görülmektedir. Bir diğer ifadeyle gerçekleşen kayıp tutarlarının GH-ASV-skw st-VaR modelince öngörülen kayıp tutarlarını aşması durumunda bu aşımların yol açabileceği kayıp oranının \%3,335 seviyesine ulaşabileceği ifade edilebilir. Bu nedenle Dolar-TL'ye 1.000 TL yatırım yapan bir yatırımcının \%99 güvenle her 100 günde 99 kez karşılaşabileceği kayıp oranlarının \%2,73’ü aşamayacağı, fakat kalan \%1'lik hata payının gerçekleşmesi durumunda her 100 günde $1 \mathrm{kez}$ kayıp oranlarının \%2,73 seviyesini (27,3 TL'yi) aşabileceği ve bu aşımlar dikkate alındığında da maksimum kayıp oranının \%3,335 seviyesine (33,5 TL'ye) ulaşabileceği ifade edilebilir. Euro-TL için elde edilen sonuçlar incelendiğinde ise bu döviz kuruna dayalı yatırımlardan dolayı \%99 güven düzeyinde bir gün sonraki maksimum kayıp oranının \%1,827 olabileceği anlaşılmaktadır. Bir diğer ifade ile bir yatırımcının Euro-TL'ye 1.000 TL yatırım yapması durumunda $\% 99$ güvenle yatırımcı bu yatırımından dolayı bir gün sonra maksimum 18,27 TL $(1.000 \mathrm{TL} * \% 1,827=18,27 \mathrm{TL})$ kaybedebilecektir. GH-ASV-skw-st-ES sonuçlarına bakıldığında ise \%1'lik hata payının gerçekleşmesi durumunda kayıp oranının \%2,255 seviyesine yükselebileceği anlaşılmaktadır. Bu nedenle Euro-TL'ye 1.000 TL yatırım yapan bir yatırımcının \%1'lik hata payının gerçekleşmesi durumunda kayıp tutarının 18,27 TL'den 22,55 TL'ye çıkabileceği ifade edilebilir. Dolayısıyla, mevcut bulgular incelenen dönem için Dolar-TL'ye dayalı yatırımların piyasa riskinin Euro-TL'ye göre daha yüksek olduğu sonucuna işaret etmektedir. Ayrıca, analizlerde alternatif güven düzeylerinin (\%99,5 ve \%95 gibi) kullanılması durumunda da bulguların piyasa riski açısından benzer sonuçlara işaret ettiği anlaşılmaktadır. Bu nedenle Dolar-TL'ye yatırım yapmanın Euro-TL'ye yatırım yapmaya göre daha riskli olduğu ifade edilebilir.

\section{DEĞERLENDİRME VE SONUÇ}

Türkiye gibi yapısal olarak cari açık veren gelişen piyasa ekonomilerinde döviz kurlarında yaşanan beklenmedik fiyat hareketlerinin önemli makro ekonomik ve finansal etkileri olabilmektedir. $\mathrm{Bu}$ nedenle bu tür gelişen piyasa ekonomilerinde etkin finansal analizlerin yapılabilmesi, doğru yatırım kararlarının verilebilmesi ve ekonomi politikalarının başarılı bir şekilde uygulanabilmesi için döviz kuru volatilitesinin daha etkin bir şekilde ölçülmesinin ve temel dinamiklerinin daha iyi bir şekilde anlaşılmasının önemli olduğu düşünülmektedir. Bu nedenle bu çalışmada Nakajima ve Omori (2012) tarafindan geliştirilen GH-ASV-skw st modeli Türk döviz piyasasına uygulanmıştır. Türk döviz piyasasını temsilen Dolar-TL ve Euro-TL kurlarından yararlanılmıştır. Böylece çalışmada şu üç temel soruya yanıt aranmıştır: (i) Bayesyen yaklaşımına dayalı MCMC algoritması kullanılarak tahmin edilen GH-ASV-skw st modeli etkin bir şekilde Türk döviz piyasalarına uygulanabilmekte midir ?. (ii) Güncel ve gelişmiş bir model olarak GH-ASV-skw st modelinin Türk döviz piyasasının volatilite dinamikleri konusunda sunduğu bilgiler nelerdir ?. (iii) Bu modelin sunduğu zamanla değişen şartlı stokastik volatilite değerlerine bağlı olarak hesaplanan GHASV-skw st -VaR ve GH-ASV-skw st-ES değerleri uygulamada oldukça önemli bir yer tutan döviz kuru riskinin ölçümü konusunda ne tür bilgiler sunmaktadır?

$\mathrm{Bu}$ kapsamda elde edilen bulgular incelendiğinde, öncelikle çalışma bulgularının GHASV-skw st modelinin Türk döviz piyasasına etkin bir şekilde uygulanabileceğine işaret ettiğ anlaşılmaktadır. Çünkü bulgular otokorelasyon fonksiyonunun hızlıca azaldığını ve örneklem patikasının göreceli olarak istikrarlı bir seyir izlediğini göstermektedir. 
İkinci olarak, Dolar-TL ve Euro-TL kurlarının volatilite dinamiklerine bakıldığında, yüksek volatilite kalıcılığının ve asimetrik tepkinin her iki döviz kuru için de geçerli olduğu anlaşılmaktadır. Yüksek volatilite kalıcılığının geçerli olması beklenmedik iktisadi ve finansal gelişmeler sonrasında Türk döviz piyasasında yaşanabilecek bir volatilite şokunun etkilerinin uzun süreliceği anlamına gelmektedir. Bu etkinin Dolar-TL kuruna göre Euro-TL kuru için daha belirgin olduğu da belirtilmelidir. Asimetrik tepkinin geçerli olması ise TL'nin Dolar ve Euro karşısında değer kaybetmesinin değer kazanması durumuna göre volatilite üzerinde daha fazla etkili olduğu anlamına gelmektedir. $\mathrm{Bu}$ sonuç da daha önce de belirtildiği gibi döviz cinsinden önemli oranda diş borcu bulunan gelişen piyasa ekonomileri için beklenen bir durumdur. Çünkü, bu tür ülke ekonomilerinin yerel para birimlerinin değer kaybetmesi diş borç ödemelerinin yanı sıra enflasyon ve faiz oranları gibi diğer çeşitli makro ekonomik ve finansal göstergeleri de negatif bir şekilde etkileyerek ülke ekonomilerini daha riskli hale getirebilmektedir. $\mathrm{Bu}$ tür gelişmeler de volatilitenin daha da artması sonucunu doğurabilmektedir. Volatilite değişkenliği katsayısına gelince, bu katsayının Dolar-TL kuru için daha yüksek değerler aldı̆̆ı gözlemlenmektedir. Bu bulgu da Dolar-TL volatilitesinin öngörülebilirliğinin Euro-TL volatilitesine göre daha zor olduğu anlamına gelmektedir.

Üçüncü olarak, GH-ASV-skw st-VaR ve GH-ASV-skw st-ES değerlerine bakıldığında Dolar-TL ve Euro-TL'de taşınabilecek pozisyonlar için bir yatırımcın ve / veya bir finansal kurumun önemli oranda kayba uğrayabileceği anlaşılmaktadır. Bu kaybın özellikle DolarTL'de taşınabilecek pozisyonlar için daha da yüksek olduğu belirtilmelidir.

Çalışma bulgularının yatırımcılar, finansal ve reel sektör kuruluşları ile politika yapıcılar açısından önemli olduğu düşünülmektedir. Yatırımcılar açısından bakıldığında Dolar-TL kurunun volatilite değişkenliğinin ve piyasa riskinin daha yüksek olması nedeniyle bu döviz kurunu içerecek portföylerin yönetiminde göreceli olarak daha temkinli davranılması gerektiği anlaşılmaktadır. Fakat, her iki döviz kuru için de beta katsayısının pozitif çıkması nedeniyle bu para birimlerinden oluşturulabilecek portföylerden pozitif getiri elde etme olasılığının negatif getiri elde etme olasılığına göre daha yüksek olduğu ifade edilebilir. Finansal kuruluşlar açısından bakıldığında ise GH-ASV-skw st -VaR ve GH-ASV-skw st-ES değerlerinin Dolar-TL kuru için daha yüksek çıkması nedeniyle bu döviz kurunu göreceli olarak daha yoğun bir şekilde içeren bilançolara sahip bankaların daha yüksek oranda sermaye ayırmalarının gerekebileceği anlaşılmaktadır. Ayrıca, BIS (Bank for International Settlements, BIS, 2016) 2022 yılında uygulanması planlanan Basel 4 kapsamında bankaların piyasa riskinden dolayı maruz kalabilecekleri kayıp tutarlarının hesaplanmasında ES değerlerinin kullanılmasını tavsiye etmiştir. Bu nedenle, bu çalışmada GH-ASV-skw st modeli kapsamında ES değerlerinin hesaplanmış olmasının da ilgili güncel gelişme kapsamında özellikle bankalar açısından önemli olduğu düşünülmektedir. Ayrıca, gerek yatırımcıların gerekse finansal kurumların bir çok finansal analizde (opsiyonların fiyatlanması, portföy yönetimi, piyasa riski analizi, optimal hedge rasyolarının belirlenmesi gibi) bir volatilite değişkenine ihtiyaç duydukları bilinmektedir. Bu kapsamda, GH-ASV-skw st modelinin Bayesyen yaklaşımına dayalı MCMC algoritması ile Türk döviz piyasalarına başarılı bir şekilde uygulanabiliyor olması nedeniyle ilgili finansal analizlerde bu model tarafindan sunulan stokastik volatilite değerlerinin kullanılmasının daha etkin sonuçlara ulaşılabilmesi açısından da önemli olabileceği düşünülmektedir. Reel sektör kuruluşları açısından bakıldığında ise yüksek piyasa riski nedeniyle Dolar-TL ve Euro-TL'ye bağlı olarak borçlanan, ithalat / ihracat yapan veya açık pozisyon ile çalışan kuruluşların bu tür risklerin 
negatif etkilerinden en az düzeyde etkilenebilmeleri için türev piyasalardan hedging amaçlı olarak yararlanmalarının oldukça önemli olduğu düşünülmektedir. Politika yapıcılar açısından bakıldığında ise özellikle merkez bankasının para politikası uygulamalarının etkinliğinin bir göstergesi olarak değerlendirdiği döviz kuru volatilitesinin daha etkin bir şekilde ölçülüp izlenebilmesi için sadece döviz kurları üzerine yazılmış opsiyonlara dayalı olarak hesaplanan zımni volatiliteyi değil GH-ASV-skw st modeli gibi gelişmiş güncel modeller tarafından sunulan volatiliteyi de dikkate alabileceği düşünülmektedir. Çünkü, GH-ASV-skw-st modeli hem finansal zaman serilerinin çeşitli karakteristik özelliklerini dikkate alabilmekte hem de volatiliteyi gözlemlenemeyen, piyasa dönük bilgi akışının sonucu olarak oluşan stokastik bir süreç olarak modelleyebilmektedir.

Bundan sonraki çalışmalarda ise bu çalışmada kullanılan modelin diğer Türk finansal varlıklarına da uygulanabileceği ve / veya bu modelin performansının diğer çeşitli modellerin performansı ile karşılaştırılabileceği düşünülmektedir.

\section{KAYNAKLAR}

Abiyev, Vasif (2015), "Time-varying Beta and Its Modeling Techniques for Turkish Industry Portfolio", İktisat İşletme ve Finans, 30(352), pp. 79-108.

Basel Committee on Banking Supervision (2016), "Minimum Capital Requirements for Market Risk", https://www.bis.org/bcbs/publ/d352.htm (Erişim Tarihi, 4 Şubat 2020).

Başç1, Erdem- Kara, Hakan (2011), "Finansal İstikrara ve Para Politikası”, İktisat İşletme ve Finans, 26 (302), ss.9-25.

Berumet, M. Hakan-Yalçın, Yeliz-Yıldırım, Jülide, O. (2011), "The Inflation and Inflation Uncertainty Relationship for Turkey: A Dynamic Framework", Empirical Economics, 41, pp. 293-309.

Dimitrakopoulos, Stefanos (2017), "Semiparametric Bayesian Inference for Time-varying Parameter Regression Models with Stochastic Volatility”, Economics Letters, 150, pp.10-14.

Göktağ, Özlem-Hepsă̆, Aycan (2016), “BIST100 Endeksinin Volatil Davranışlarının Simetrik ve Asimetrik Stokastik Volatilite Modelleri ile Analizi", Ekonomik Yaklaşım, 27 (99), ss.1-15.

Ishihara, Tsunehiro-Omori, Yasuhiro (2012), "Efficient Bayesian Estimation of a Multivariate Stochastic Volatility Model with Cross Leverage and Heavy-Tailed Errors"', Computational Statistics \& Data Analysis, 56(11), pp. 3674-3689.

Jensen, Mark J.-Maheu, John M. (2014), "Estimating Semiparametric Asymmetric Stochastic Volatility Model with a Dirichlet Process Mixture", Journal of Econometrics, 178, pp. 523-538.

King, Michael R.-Osler, Carol L.- Rime, Dagfinn (2011), "Foreign Exchange Market Structure, Players and Evolution", Norges Bank Working Paper No:10, http://www .unich.it/ vitale/ Rime-2.pdf ( Erişim Tarihi, Haziran 2019). 
Krichene, Noureddine (2003), "Modeling Stochastic Volatility with Application to Stock Returns", IMF Working Paper, No:03/125, https://www.imf.org/en/Publications/ WP/Issues /2016/ 12/30/ ( Erişim Tarihi, Nisan 2019).

Küçük, Hande - Özlü, Pınar-Talaslı, Anıl-Ünalmış, Deren-Yüksel, Canan (2013), "Likidite Yönetimi ve BIST Faiz Farkı", Türkiye Cumhuriyet Merkez Bankası Ekonomi Notlar1, Say1: 2013-25/ 23 Ekim 2013, http://www.academia.edu /4870421/Likidite _Y\%C3\% B6netimi_ve_BIST_Faiz_Fark\%C4\%B1 ( Erişim Tarihi, Şubat 2019).

Lafosse, Patricia Lengua-Rodriguez, Gabriel (2018), “An Empirical Application of a Stochastic Volatility Model with GH Skew Student's t-Distribution to the Volatility of Latin-American Stock Returns", The Quarterly Review of Economics and Finance, 69, pp. $155-173$.

Larsson, Karl-Nossman, Marcus (2011), "Jumps and Stochastic Volatility in Oil Prices: Time Series Evidence”, Energy Economics, 33, pp. 504-514.

Ranciere, Romain-Tornell, Aaron-Vamvakidis-Athanasios(2010), "A New Index of Currency Mismatch and Systemic Risk", IMF Working Paper, WP /10/263, file:///C:/Users /asus/Downloads/_wp10263.pdf (Erişim Tarihi, Nisan 2019).

Nakajima, Jouchi-Omori, Yasuhiro (2009), "Leverage, Heavy-tails and Correlated Jumps in Stochastic Volatiliy Models", Computational Statistics and Data Analysis, 53, pp. 2335-2353.

Nakajima, Jouchi-Omori, Yasuhiro (2012), " Stochastic Volatility Model with Leverage and Asymmetrically Heavy-Tailed Error Using GH Skew Student's t-distribution", Computational Statistics and Data Anlysis, 56, pp. 3690-3704.

Özün, Alper-Türk, Mehmet (2008), “Döviz Kurlarının Öngörüsünde Stokastik Oynaklık Modelleri”, İktisat İşletme ve Finans, 23 (265), ss. 50-67.

Pan, Qi ve Li, Yong (2013), "Testing Volatility Persistence on Markov Switching Stochastic Volatility Models", Economic Modelling 35, pp. 45-50.

Selçuk, Faruk (2004), "Free Float and Stochastic Volatility: The Experience of a Small Open Economy", Physica A: Statistical Mechanics and its Applications, 342, pp. 3-4.

Shirota, Shinichiro-Hizu,Takayuki-Omori, Yasuhiro (2014), "Realized Stochastic Volatility with Leverage and Long Memory", Computational Statistics and Data Analysis, 76, pp. 618-641.

Wang, Ping (2011), "Pricing Currency Options with Support Vector Regression and Stochastic Volatility Model with Jumps", Expert Systems with Applications, 38,pp. 17. 
